\title{
MEMENTO MORI: A MORTE ENTRE A DOGMÁTICA E A ZETÉTICA
}

\section{MEMENTO MORI: THE DEATH BETWEEN THE DOGMATIC AND THE ZETETIC}

\section{${ }^{1}$ Lucas Costa de Oliveira}

\section{RESUMO}

O presente artigo tem como objetivo realizar um estudo acerca da prática da eutanásia e do suicídio assistido. Em um primeiro momento, apontam-se alguns pressupostos indispensáveis à construção do artigo. $\mathrm{O}$ desenvolvimento ocorre através da dicotomia dogmática/zetética. Na seção dogmática, analisa-se o ordenamento jurídico brasileiro, passando pela Constituição da República, Código Civil, Código Penal e a Resolução CFM n.1805/2006. Ainda, analisase o tratamento dado à eutanásia e ao suicídio assistido em outros ordenamentos jurídicos. $\mathrm{Na}$ seção zetética, acolhe-se o pensamento de Friedrich Nietzsche para fundamentar a autonomia para morrer como afirmação da vida. Conclui-se pela possibilidade de fundamentação, em termos dogmáticos e zetéticos, da prática da eutanásia e do suicídio assistido.

Palavras-chave: Eutanásia, Suicídio assistido, Dogmática, Zetética, Memento mori

\begin{abstract}
The present paper aims to conduct a study about the practice of euthanasia and assisted suicide. At first, it is pointed a few essentials assumptions to the construction of the paper. The development occurs through the dogmatic/zetetic dichotomy. In the dogmatic section, it is analyzed the Brazilian legal system through the Constitution, Civil Code, Penal Code and Resolution CFM n.1805/2006. It is also analyzed the treatment given to euthanasia and assisted suicide in comparative law. In the zetetic section, it is chosen the thought of Friedrich Nietzsche to support the autonomy to die as a life affirmation. The conclusion indicate the possibility of reasoning in dogmatic and zetetic terms the practice of euthanasia and assisted suicide.
\end{abstract}

Keywords: Euthanasia, Assisted suicide, Dogmatic, Zetetic, Memento mori

\footnotetext{
${ }^{1}$ Mestrando na Pontifícia Universidade Católica de Minas Gerais - PUC/MG, Minas Gerais (Brasil). Professor da Universidade Federal de Ouro Preto - UFOP, Minas Gerais (Brasil). E-mail: lucascoliveira01@ gmail.com
} 


\section{INTRODUÇÃO}

Conta a história apócrifa que quando um general da Roma antiga retornava em glória das suas batalhas, havia sempre um escravo cujo o trabalho seria lembrar que o triunfo não seria eterno. Memento Mori - lembra-te que morrerás - era a expressão que o escravo sussurrava nos ouvidos do general.

Vida e morte, tensão imanente, inevitável. É nessa perspectiva que surge o tema que o artigo pretende abordar. A morte pode ser estudada através de uma ótica obscura, melancólica, preconceituosa, representando uma negação da vida. Por outro lado, a morte pode ser entendida como afirmação da vida, da pessoalidade e identidade do ser humano, como um exercício de autonomia para além da vida.

Desse modo, objetiva-se realizar um estudo sobre a eutanásia e o suicídio assistido que aponte a segunda concepção. A morte pode ser também uma manifestação da dignidade da pessoa humana. Para tanto, a fundamentação se divide em três pontos essenciais. Em um primeiro momento, analisam-se pressupostos indispensáveis à construção do artigo. $\mathrm{O}$ desenvolvimento se realiza a partir da dicotomia entre dogmática e zetética. Na seção dogmática, analisa-se o ordenamento jurídico brasileiro, passando pela Constituição da República, Código Civil, Código Penal e a Resolução CFM n.1805/2006. Ainda, analisa-se o tratamento dado à eutanásia e ao suicídio assistido em outros ordenamentos jurídicos. Na seção zetética, acolhe-se o pensamento de Friedrich Wilhelm Nietzsche para fundamentar a autonomia para morrer como afirmação da vida.

Trata-se de um assunto de fundamental importância para a construção de um Estado Democrático de Direito que respeite o pluralismo sociocultural, bem como possibilite a cada pessoa se tornar aquilo que pretende ser. Ademais, a legislação não é clara, tratando o tema de maneira periférica. É preciso conversar, debater, estudar sobre a morte - em aspectos jurídicos, filosóficos e sociológicos. 


\section{CONSIDERAÇÕES PRELIMINARES}

Antes de adentrar especificamente no tema proposto, faz-se necessário a explicitação de alguns pontos que são fundamentais ao desenvolvimento da pesquisa, consistindo pressupostos indispensáveis à sua correta compreensão. Destaca-se que esses pressupostos não possuem correlação direta entre si, mas estão todos relacionados ao tema central.

Dessa sorte, analisar-se-á os seguintes pontos: a distinção entre dogmática e zetética, uma vez o desenvolvimento da pesquisa se dar face a essa dicotomia; a conceituação de termos que serão reiteradamente utilizados, como eutanásia, distanásia, mistanásia e suicídio assistido; e, por fim, realizar-se-á um breve estudo sobre a relação médico-paciente, na medida em que consiste no pano de fundo para a prática da eutanásia e suicídio assistido.

\subsection{Zetética e Dogmática}

O estudo do Direito pode se dar através de diferentes perspectivas. Tércio Sampaio Ferraz Júnior, a partir dos ensinamentos de Theodor Viehweg, apresenta um dos enfoques possíveis, qual seja, o zetético/dogmático.

Zetética tem sua origem no vocábulo zetein, tendo como significado perquirir, ao passo que dogmática tem sua origem no vocábulo dokein, tendo como significado ensinar, doutrinar. O estudo da etimologia dessas palavras tem o condão de apresentar a principal diferença entre os dois enfoques: enquanto a zetética está voltada à pergunta, deixando os conceitos básicos, as premissas e os princípios abertos à dúvida e caracterizando-se por seu caráter hipotético e problemático, a dogmática está voltada à resposta, tendo os conceitos básicos, as premissas e os princípios postos de modo absoluto e caracterizando-se por seu caráter voltado à decidibilidade. A zetética desintegra opiniões, pondo-as em dúvida, enquanto a dogmática releva o ato de opinar. $\mathrm{O}$ aspecto zetético tem função especulativa explícita e são infinitas, ao passo que o aspecto dogmático têm uma função diretiva (induz o espectador a adotar certa conduta), e são finitas. Zetética é ser, dogmática dever-ser (FERRAZ JÚNIOR, 2007).

Elucidativo o exemplo dado por Tércio Sampaio (2007, p.40):

Sócrates estava sentado à porta de sua casa. Nesse momento, passa um homem correndo e atrás dele vem um grupo de soldados. Um dos soldados então grita: agarre esse sujeito, ele é um ladrão! Ao que responde Sócrates: que você entende por "ladrão"? Nota-se aqui dois enfoques: o do soldado que parte da premissa de que o significado de ladrão é uma questão já definida, uma solução já dada, sendo seu problema agarrálo; e o de Sócrates, para quem a premissa é duvidosa e merece um questionamento prévio. 
Destarte, o soldado parte de um pensamento dogmático e Sócrates de um pensamento zetético. O que deve ficar claro, é que o enfoque dogmático tem como característica fundamental a inegabilidade dos pontos de partida, ou seja, o jurista parte da lei como premissa absoluta e através dela organiza e sistematiza o ordenamento.

Tem-se a sociologia jurídica, história do direito, filosofia do direito, criminologia, antropologia jurídica, medicina legal e metodologia jurídica como exemplos de matérias zetéticas, ao passo que o Direito Civil, Constitucional, Penal, Tributário, Administrativo são exemplos de matérias dogmáticas. Não obstante tal divisão, é certo que existe um interseção entre a dogmática e a zetética, sendo enfoques que se encontram em tensão.

\subsection{Eutanásia, distanásia, mistanásia, ortotanásia e suicídio assistido}

O termo "eutanásia" pode ser observado sob diferentes perspectivas, como a religiosa, a filosófica e a jurídica, razão pela qual se faz necessário a delimitação do que se entende por essa expressão.

Diz-se que a primeira utilização do termo se deu pelo hesteriador Suetônio, no século II d.C, ao descrever a morte do imperador Augusto (SIQUEIRA-BATISTA; SCHRAMM, 2004; PESSINI; BARCHIFONTAINE, 2007). Ipsis litteris: "A sua morte foi suave, e como a havia desejado; porque, quando ouvia dizer que qualquer morrera sem dôr, desejava, servindo-se d'uma expressão grega, que elle e os seus morressem também assim felizes" (SUETÔNIO, 2014, p.74).

Segundo Maria de Fátima Freire de Sá e Bruno Torquato de Oliveira Naves (2011, p. 311), o termo eutanásia “[...] deriva do grego eu (boa), thanatos (morte), podendo ser traduzido como 'boa morte', 'morte apropriada', morte piedosa, morte benéfica, fácil, crime caritativo, ou, simplesmente, direito de matar".

Dessa maneira, a origem dessa expressão tem ligação com o "[...] estoicismo, ${ }^{1}$ que aceitava que o sábio podia e devia assumir sua própria morte quando a vida não tivesse mais sentido para ele". (PESSINI; BARCHIFONTAINE, 2007, p. 378).

\footnotetext{
1 “O ponto crucial da filosofia estóica era uma ética de consolo através da identificação com a ordem moral imparcial e inevitável do universo. É uma ética da serenidade auto-suficiente e benevolente, em que a paz do homem sábio o deixa indiferente à pobreza, à dor e à morte, assemelhando-se assim à paz espiritual de Deus" (BLACKBURN, 1977, p. 128).
} 
Somente no século XVII, com o filósofo inglês Francis Bacon, o termo ganha a conotação atual, relacionada ao ato de pôr fim à vida da pessoa enferma. Dessa sorte, somente se falaria em eutanásia em casos de pessoas sob as quais não existam esperanças de vida em forma digna. A partir de então, eutanásia passa a ser entendida como a ação médica que visa abreviar a vida de pessoas que se encontram em grave sofrimento de doença e sem perspectiva de melhora, desde que haja consentimento desta (SÁ; NAVES, 2011).

A eutanásia pode ser ativa, quando há uma ação a fim de se abreviar a vida, bem como passiva, quando há a omissão de uma medida que poderia prolongar a vida da pessoa. A essa segunda modalidade, a doutrina também dá o nome de ortotanásia.

Ainda a respeito da ortotanásia, de acordo com a resolução CFM n. 1.805/2006, pode ser entendida como a limitação ou suspensão de procedimentos e tratamentos que prolonguem a vida do doente em fase terminal de doença grave e incurável, desde que receba assistência física, psíquica, social e espiritual (CONSELHO FEDERAL DE MEDICINA, 2014).

Distanásia é o oposto da eutanásia. Enquanto nessa há o encurtamento da vida, naquela há o prolongamento, na maior medida do possível e mesmo que inútil, da vida humana, combatendo a morte a todo e qualquer custo. Mistanásia, por sua vez, é a morte miserável, antes da hora, de caráter iminentemente social. Por fim, tem-se a figura do suicídio assistido. Conforme se analisou, a eutanásia consiste na morte a partir de um terceiro, qual seja, o médico. Já nessa outra figura, não há ação ou omissão direta de um indivíduo (médico ou não), que apenas orienta, auxilia ou observa o paciente na sua atitude de pôr fim à vida. (SÁ; NAVES, 2011).

Isso posto, cabe salientar que a pesquisa terá como enfoque os institutos da eutanásia, nas suas modalidades ativa e passiva, bem como do suicídio assistido. Tal escolha se fundamenta em razão de serem as modalidades em que há um maior grau de autonomia privada. Ademais, não há qualquer óbice - ao menos juridicamente -, à prática da distanásia, bem como a mistanásia se trata de uma questão social.

\subsection{A relação médico-paciente}

O tema proposto na presente pesquisa tem estreita ligação com a relação médicopaciente, consistindo no pano de fundo em que se passa grande parte dos casos relativos a autonomia para morrer. Assim, para que se possa compreender e sustentar práticas como a 
eutanásia e o suicídio assistido, é mister sedimentar o contexto em que tais direitos podem ser exercidos.

A relação médico-paciente é um fenômeno complexo. Não se pretende esgotar todos seus aspectos, o que requereria uma pesquisa por si só, mas apenas apontar aqueles indispensáveis à compreensão do que se entende dessa relação na contemporaneidade.

Duas características podem ser destacadas na relação médico-paciente hodierna. A primeira é referente à natureza dessa relação. Se outrora tinha um caráter essencialmente paternalista, pautada na confiança e amizade, simbolizada na figura do médico de família, hoje tem natureza contratual, consumerista, despessoalizada, tendo como marca os grandes hospitais e centros de saúde (SOUZA, 2014). A segunda característica marcante é a não objetificação do homem, que ocorre quando há "imposição ao paciente do status de mero objeto, quando não é respeitada sua vontade no tratamento" (STANCIOLI, 2004, p. 23, grifo no original).

Ainda em relação à segunda característica, entende-se que essa ocorre através de uma relação cognitivo-científica, onde o médico observa, compreende e domina o paciente, de maneira semelhante ao método positivista de ciência pertencente a áreas distintas da medicina, como a física. Destarte, da mesma maneira que o físico tenta dominar a natureza, o médico tenta dominar o paciente, não o tratando como pessoa, indivíduo, ser humano, mas como um mero objeto que precisa ser enquadrado em uma das hipóteses (STANCIOLI, 2004).

Segundo Brunello Souza Stancioli (2004), a objetificação se dá em, pelo menos, três formas. A primeira diz respeito ao status imposto ao paciente através do isolamento e da falta de contato com o mundo externo, gerando uma segregação. A segunda forma é a classificação científica, na qual o paciente perde seu caráter de pessoa para assumir o contorno específico de sua doença, sendo estigmatizado. O terceiro, por sua vez, é a reconstrução do seu ego, consistindo na internalização das recomendações médicas pela única razão de temor das consequências.

Acontece que a relação médico-paciente passou por uma evolução. Assim sendo, a tendência é o paciente não ser visto como mero consumidor ou objeto, mas sim como um ser humano, dotado de autonomia, consistindo no principal personagem da relação (SOUZA, 2014).

A relação médico-paciente que figura como pano de fundo do presente estudo é aquela onde resgata-se a pessoa na sua individualidade. Como bem determina Brunello Stancioli (2004, p. 109), "a tradição hipocrática, que priorizava o (suposto) bem-estar do paciente, de maneira exógena à sua crítica e sua vontade, parece ter encontrado - ao menos em termos teóricos - o 
seu crepúsculo”. Dessa forma, a relação médico-paciente cristaliza-se pela repersonalização, busca do consenso e aceitação da diferença.

Como se percebe, a autonomia do paciente tem posição nevrálgica no âmbito da relação médico-paciente proposta. Dessarte, é mister analisar o modo como essa autonomia pode ser exercida para que tenha validade e atinja seus objetivos.

A manifestação de vontade, nesses casos, pode ser exercida através do termo de consentimento livre e esclarecido (TCLE) ou através das diretivas antecipadas de vontade. É necessário destacar que em ambos os casos existem pressupostos indispensáveis à validade jurídica dessas manifestações. Por se tratarem de um negócio jurídico, devem-se adequar aos requisitos do art. 104 do Código Civil. Esclarece Iara Antunes de Souza (2014, p. 22), que a manifestação deve ser "[...] esclarecida, oriunda de uma informação correta e suficiente; ter o agente que a manifesta perfeito discernimento; e inexistência de qualquer condicionante que a vicie, tais como erro, o dolo, a coação, o estado de perigo e a lesão".

O termo de consentimento livre e esclarecido é a exteriorização da vontade do paciente capaz e consciente, em relação ao procedimentos médicos que devem ser realizados, após ter sido plenamente informado. O TCLE será composto

[...] pelas informações prestadas com a linguagem acessível ao paciente, a não informação pelo reconhecimento do direito a não saber do paciente, os procedimentos ou terapêuticas que serão utilizados, suas justificativas e seus objetivos, os desconfortos e riscos previstos e previsíveis, os benefícios esperados, a existência ou não de métodos alternativos, a decisão do paciente em consentir ou não, assinatura do paciente, de seu representante legal ou de pessoa por ele indicada e autorizada (SOUZA, 2014, p. 28).

As diretivas antecipadas de vontade, também denominadas como testamentos vitais, consistem de "um ato jurídico capaz de antecipar a vontade individual, a fim de que seus efeitos possam ser verificados para o futuro" (SÁ; MOUREIRA, 2012, p. 183). São utilizadas nas hipóteses em que não há possibilidade de manifestação de vontade do paciente no momento, como nos casos de inconsciência.

Em relação às diretivas antecipadas de vontade, interessante destacar o Ato de Autodeterminação do Paciente ou Patient Self-Determination Act (PSDA), texto normativo estadunidense, em vigor desde 1991. Com intuito de alavancar a autonomia privada do paciente, o PSDA institui as diretivas avançadas a serem utilizadas em caso de incapacidade superveniente (SÁ; NAVES, 2011).

Maria de Fátima de Sá e Bruno Torquato de Oliveira Naves (2011, p.87, grifo nosso), ensinam que essas diretivas avanças podem se dar através de três instrumentos: 
O living will ou "testamento em vida" pretende estabelecer os tratamentos médicos indesejados, caso o paciente incorra em estado de inconsciência ou esteja em estado terminal. [...]. Pelo durable power of attorney for health care (poder duradouro de representante para cuidados com a saúde - ou simplesmente, mandato duradouro) estabelece-se um representante para decidir e tomar as providências cabíveis pelo paciente. A advanced core medical directive (diretiva do centro médico avançado) diz respeito ao estado terminal. Por esse instrumento o paciente estabelece os procedimentos a que não quer se submeter e nomeia um representante.

Situação bastante complexa é a que trata da autonomia para morrer nos casos de incapacidade. Seria possível a prática da eutanásia e suicídio assistido? Teriam seus representantes legitimidade para tal decisão? Deve-se levar em consideração a vontade dos incapazes?

Não há resposta pronta nesses casos, devendo haver uma construção racional caso a caso, respeitando princípios como o do melhor interesse e da dignidade da pessoa humana. Defendese o exercício da autonomia dos incapazes, na maior medida do possível e quando possível, afinal

[...] o direito é produto de um fluxo comunicativo em que conceitos jurídicos não se tratam de realidades consolidadas, imutáveis e indiscutíveis, mas são reconstruídos através de uma prática argumentativa em constante processo de construção. A presunção de incapacidade de um indivíduo menor de 16 anos, ou menor de 18 anos, é absoluta? Não poderiam estes indivíduos decidir sobre questões existenciais que digam respeito a sua autobiografia, ou a presunção de incapacidade impede seja construída sua pessoalidade? Cada vez mais estamos diante de situações fáticas em que o exercício da autonomia dos incapazes deve ser levado em consideração, ainda que a própria lei tenha estabelecido uma presunção de incapacidade pela idade (SÁ; MOUREIRA, 2012, p. 169-170).

Dessa maneira, conclui-se que "mais que um tratamento ou busca do bem - estar físico, o indivíduo deve ter o poder de escolha da forma de terapia que lhe é mais adequada: o grande tribunal será a própria consciência" (STANCIOLI, 2004, p. 111). A relação médico-paciente ideal, é aquela em que há diálogo, consentimento, consenso, informação, e, principalmente, autonomia.

\section{APONTAMENTOS DOGMÁTICOS}

Neste ponto analisar-se-á o ordenamento jurídico brasileiro no que diz respeito à eutanásia e ao suicídio assistido, passando pela Constituição da República, Código Civil, Código Penal e resolução CFM n. 1.805/2006. Analisar-se-á, por fim, como outros ordenamentos jurídicos abordam o tema. 


\title{
3.1 Constituição da República
}

A Constituição da República Federativa do Brasil de 1988 aponta, logo em seu preâmbulo, diretivas que devem ser observadas na hermenêutica e aplicação das normas de todo o ordenamento brasileiro.

Inicia-se com a instituição de um Estado Democrático, onde se deve assegurar direitos sociais e individuais, liberdade, bem estar, igualdade e justiça, a fim de que se alcance uma sociedade fraterna, pluralista e sem preconceitos. No pensamento de Dalmo de Abreu Dallari (2010), o Estado Democrático é um ideal possível de ser atingido, desde que atingidos os seguintes requisitos: eliminação da rigidez formal; supremacia da vontade do povo; preservação da liberdade; e preservação da igualdade.

Necessário ressaltar de antemão, que o Supremo Tribunal Federal já sedimentou o entendimento que o preâmbulo não constitui norma cogente, servindo de norte axiológico ao ordenamento pátrio. Nas palavras da ministra Cármen Lúcia:

\begin{abstract}
Devem ser postos em relevo os valores que norteiam a Constituição e que devem servir de orientação para a correta interpretação e aplicação das normas constitucionais e apreciação da subsunção, ou não, da Lei 8.899/1994 a elas. Vale, assim, uma palavra, ainda que brevíssima, ao Preâmbulo da Constituição, no qual se contém a explicitação dos valores que dominam a obra constitucional de 1988 [...]. Não apenas o Estado haverá de ser convocado para formular as políticas públicas que podem conduzir ao bem-estar, à igualdade e à justiça, mas a sociedade haverá de se organizar segundo aqueles valores, a fim de que se firme como uma comunidade fraterna, pluralista e sem preconceitos. É certo que parte da doutrina não considera o Preâmbulo como dotado de força normativa [...]. E, referindo-se, expressamente, ao Preâmbulo da Constituição brasileira de 1988, escolia José Afonso da Silva que "O Estado Democrático de Direito destina-se a assegurar o exercício de determinados valores supremos. "Assegurar", tem, no contexto, função de garantia dogmático- constitucional; não, porém, de garantia dos valores abstratamente considerados, mas do seu "exercício". Este signo desempenha, aí, função pragmática, porque, com o objetivo de "assegurar", tem o efeito imediato de prescrever ao Estado uma ação em favor da efetiva realização dos ditos valores em direção (função diretiva) de destinatários das normas constitucionais que dão a esses valores conteúdo específico.” (BRASIL, 2008, p. 12-14).
\end{abstract}

Não obstante à falta de normatividade, o preâmbulo tem grande importância, na medida em que é possível captar a intenção dos constituintes originários no momento da criação constitucional. Valores como pluralidade, liberdade e justiça, devem ser assegurados de forma efetiva, seja na interpretação ou aplicação das normas constitucionais e infraconstitucionais.

Ainda em diapasão com a Constituição da República de 1988, em seu art. $1^{\text {o }}$, é reforçado a instituição de um Estado Democrático, mais especificamente, Estado Democrático de Direito. A respeito desta instituição, Bernardo Gonçalves Fernandes (2010, p. 213): 
Aqui [Estado Democrático de Direito] a concepção de direito não se limita a um mero formalismo como no primeiro paradigma [Estado Liberal], nem descamba para uma materialização totalizante como no segundo [Estado Social]. A perspectiva assumida pelo direito caminha para a procedimentalização, e por isso mesmo, a ideia de democracia não é ideal, mas configurando-se pela existência de procedimentos ao longo de todo o processo decisório estatal, permitindo e sendo poroso à participação dos atingidos, ou seja, da sociedade.

Ainda estanque no art. $1^{\circ}$ da Magna Carta, em seu inciso III, faz-se necessário destacar um dos fundamentos da República Federativa do Brasil, qual seja, a dignidade da pessoa humana. Como se observa, trata-se de um conceito aberto, na medida em que a noção de dignidade é inerente a cada pessoa, bem como trata-se de um conceito de caráter axiológico, uma vez estar atrelado à concepções morais, espirituais, valorativas de cada ser humano. Dessa sorte, Alexandre de Moraes (2002, p. 129) entende que "esse fundamento afasta a ideia de predomínio das concepções transpessoalistas de Estado e Nação, em detrimento da liberdade individual”. Ainda na visão do referido constitucionalista:

\footnotetext{
O princípio fundamental consagrado pela Constituição Federal da dignidade da pessoa humana apresenta-se em uma dupla concepção. Primeiramente, prevê um direito individual protetivo, seja em relação ao próprio Estado, seja em relação ao demais indivíduos. Em segundo lugar, estabelece verdadeiro dever fundamental de tratamento igualitário dos próprios semelhantes (MORAES, 2002, p. 129).
}

Por fim, reputa-se indispensável a análise dos direitos e garantias fundamentais, previstos no art. $5^{\circ}$ da Constituição. Já em seu caput, reza que a todas pessoas, brasileiras ou estrangeiras, será garantido a inviolabilidade do direito à vida, bem como a liberdade. Assim sendo, a inviolabilidade do direito à vida pode ser vista sob dois prismas: um relacionado ao direito de continuar vivo, e outro relacionado ao direito de ter uma vida digna quanto à subsistência (MORAES, 2002).

Outra importante consideração acerca dos direitos fundamentais é retirada do inciso X, onde prevê-se a inviolabilidade à intimidade e à vida privada. Trata-se da proteção de um espaço eminentemente privado, onde deve-se haver um maior grau de autonomia dos indivíduos.

Enfrentando esse emaranhado de normas constitucionais, é possível de se chegar a duas conclusões diametralmente opostas. A primeira, entende ser vedada qualquer tipo de violação à vida, haja vista o art. $5^{\circ}$, caput, pregar a indisponibilidade da vida, não fazendo qualquer ressalva. Esse é o posicionamento que prevalece tanto na doutrina, quanto na jurisprudência. Alexandre de Moraes (2002, p. 180), por exemplo, entende que "[...] o direito à vida tem um conteúdo de proteção positivo que impede configurá-lo como um direito de liberdade que inclua o direito à própria morte". 
Por outro lado, é possível chegar à conclusão da admissibilidade do direito à morte própria em uma hermenêutica constitucional. Isso ocorre através da hermenêutica integrativa dos dispositivos constitucionais, onde existem princípios de caráter antagônicos.

De fato, o art. $5^{\circ}$, caput, dispõe ser inviolável a vida. Não obstante, sabe-se que nenhum direito é absoluto, nem mesmo a vida. O Supremo Tribunal Federal já chegou a esse entendimento no acórdão em que se decidiu a favor do aborto em caso de fetos anencéfalos (BRASIL, 2012), bem como há previsão no Código Penal, em seu art. 128, inciso I e II, da possibilidade de aborto no caso de gravidez resultante de estupro ou se não há outro meio de salvar a gestante (BRASIL, 1940).

Além disso, a Constituição tem como fundamento basilar a pluralidade, liberdade e dignidade da pessoa humana. Não há como efetivamente assegurar tais garantias se sedimentarse apenas uma única concepção desses direitos. Pluralidade significa diferença, democracia pressupõe aceitação das diferenças. A partir do momento em que apenas uma concepção de dignidade é aceita, acaba-se com pluralidade e a democracia.

Ademais, o art. $5^{\circ}$, inciso $\mathrm{X}$, garante a inviolabilidade da intimidade e da vida privada. Ora, existe algo mais íntimo e privado do que a própria vida? Cabe a cada pessoa, em sintonia com sua concepção de vida boa, de dignidade, planejar e organizar sua vida e morte.

Certo é que há a garantia à inviolabilidade à vida, contudo, não parece correto entender que tal garantia foi contemplada para proteger a vida contra atos do seu próprio titular. Se assim for, tal direito é uma garantia ou um dever? Parece-se mais com um dever.

Nesse sentido, Maria de Fátima e Diogo Luna (2012, p. 204-205) entendem que

[...] a pluralidade, caracterizadora da sociedade moderna, é determinante para a solução das questões existenciais. Dessa maneira, não há que se falar em solução adequada se o seu destinatário não for tomado em sua particularidade e, a partir das concepções e convicções que lhe são próprias, figurar, também - e, principalmente como autor do provimento que lhe afetará. Levantar bandeiras de um Estado Democrático de Direito e desconsiderar a participação daquele que busca a materialização do seu direito nada mais é que bradar por algo oco em sentido, desprovido, exatamente, das características que lhe conferem rótulo e sustentam seus contornos lexicais.

Dessa maneira, sendo possíveis ambas interpretações, a posição adotada nesse artigo aponta para a possibilidade da fundamentação da prática da eutanásia e suicídio assistido em nível constitucional, na medida em que representa uma hermenêutica mais adequada ao Estado Democrático de Direito e aos princípios fundamentais estabelecidos pela Constituição. 


\subsection{Código Civil}

O estudo da eutanásia e suicídio assistido sob a ótica do Código Civil de 2002 perpassa, inevitavelmente, pela questão dos direitos da personalidade e pelo princípio da autonomia privada. Iniciar-se-á com a autonomia privada.

A autonomia privada surge no âmbito jurídico através do direito privado. É entendida como o "poder de se autogovernar, e, por consequência, o detentor da autonomia tem a faculdade de se reger por um sistema de regras próprio e ter tais regras reconhecidas pelos demais" (RUGER; ROGRIGUES, 2007, p. 4).

Em um primeiro momento (Estado Liberal), foi posta como uma liberdade plena, incondicionada, aplicável especialmente às relações jurídicas patrimoniais, como a propriedade e o contrato. Não obstante, o modelo de autonomia formal entrou em colapso. A liberdade desmedida concretizou abusos e desigualdades incompatíveis com o interesse público. Dessa maneira,

[...] o conteúdo e alcance da autonomia sofreram, no início e ao longo do século XX, profundas transformações. De um mero conjunto de prerrogativas individuais do sujeito, elencadas formal e taxativamente na ordem jurídica positiva, a autonomia passou a denotar faceta positivamente reconhecida da dignidade humana (RUGER; ROGRIGUES, 2007, p. 6).

Destarte, a autonomia passou a sofrer limitações frente ao interesse público. A propriedade e o contrato passaram a atender funções sociais, as obrigações passaram a observar o princípio da boa-fé objetiva e a lealdade. Tais limitações podem ser encontradas até mesmo na denominação da autonomia. Se durante o Estado Liberal era entendida como autonomia da vontade, agora passa a ser autonomia privada.

Todavia, a relação entre direito e autonomia privada se deu, de maneira predominante, face às relações jurídicas patrimoniais. Dessa sorte, teriam as relações jurídicas existenciais, como a eutanásia e suicídio assistido, sofrido as mesmas restrições?

Se por um lado, entende-se a necessidade de intervenção estatal frente a relações que atingem outras pessoas e o interesse público, como a propriedade e o contrato, por outro, não é compreensível a intervenção desmedida, atingindo esfera exclusivamente pessoal, como é o caso da autonomia para morrer. Uma limitação desse tipo, é, inegavelmente, uma questão de juízo moral. É o que entende Renata Rodrigues e Andre Ruger (2007, p.8): 
Resta problemática, contudo, a definição do grau da força normativa e da exigência de reconhecimento que a autonomia da vontade possui nas chamadas condutas autoreflexivas, que são caracterizadas pela ínfima ou nenhuma repercussão na esfera alheia. Para pessoas de espírito mais vanguardista, o reconhecimento da incolumidade do espaço íntimo tende a ser maior. Da mesma forma, o grau de tolerância com relação a modos de vida distintos, bem como a forma de apropriação individual da tradição comum, definirá o que se entende por reverberação da autonomia da vontade, própria e alheia, no espaço público. [...]. Tal fato torna controversa a imperatividade da autonomia da vontade em tais situações, bem como a própria definição do espaço público.

Entende-se, desse modo, que a restrição à autonomia da vontade em questões existenciais que envolvam unicamente o titular do direito, não deveriam encontrar respaldo dogmático, por se tratar de uma questão de caráter moral e ético próprio de cada ser humano. A concepção de um Estado Democrático de Direito e de uma sociedade participativa e pluralista deve ter como característica nevrálgica uma autonomia privada que proteja as diversas idealizações de vida boa. Não se defende aqui, uma autonomia irrestrita, nos moldes liberais, mas apenas uma autonomia que possa assegurar a personalidade própria do indivíduo, na maior medida do possível. Logo, a autonomia para morrer deveria ser resguardada pelo ordenamento, na medida em que não cabe ao Estado impor um único padrão de vida digna. A escolha de uma modelo de vida ou de morte envolve apenas o próprio titular. Trata-se da sua vida, da sua moral, do seu direito, da sua autonomia.

Apesar de todo o exposto, o Código Civil não dispõe de regras nesse sentido. Pelo contrário, em seu art. 11 dispõe serem os direitos da personalidade intransmissíveis e irrenunciáveis, sendo vedada a limitação voluntária do seu exercício.

Faz-se necessário, de antemão, conceituar o que seriam os direitos da personalidade. Dessa forma, “[...] direitos da personalidade são aqueles que tem por objeto os diversos aspectos da pessoa humana, caracterizando-a em sua individualidade e servindo de base para o exercício de uma vida digna" (SÁ; NAVES, 2011, p. 49).

São exemplos de direito da personalidade: a vida, a integridade psíquica, o nome, a honra, a imagem e todos aqueles que se destinam à proteção da personalidade. Importante frisar que tais direitos não se encontram restritos ao Código Civil, mas se encontram em todo o ordenamento, em especial, na Constituição da República quando trata dos direitos fundamentais. Não é a forma que define um direito da personalidade, mas seu conteúdo (SÁ; NAVES, 2011; STANCIOLI, 2010).

Os direitos da personalidade são absolutos, necessários, vitalícios, intransmissíveis, irrenunciáveis, extrapatrimoniais, imprescritíveis e impenhoráveis. Dentre todas essas característica, uma se destaca para o estudo do direito de morrer, qual seja, a irrenunciabilidade. 
Tal característica é entendida como a impossibilidade de disposição do direito, não podendo se fazer cessar sua existência (SÁ; NAVES, 2011).

Assim sendo, em uma primeira interpretação, seria impossível a renúncia à vida, na medida em que seria um direito da personalidade. Não obstante, faz-se mister apresentar a visão de Brunello Stancioli acerca da renúncia do exercício dos direitos da personalidade.

O referido autor parte da distinção entre renúncia ao exercício do direito da personalidade e renúncia ao direitos da personalidade em si. No primeiro caso não há a perda da titularidade do direito, mas apenas uma abdicação ao seu exercício, consistindo uma afirmação da autonomia da vontade. Tem-se o exemplo dos frades cartuxos que renunciam ao direito de falar, que embora não exerçam, continuam titulares do direito à fala. No segundo caso há a efetiva perda do direito, ficando este extirpado da esfera do indivíduo (STANCIOLI, 2010).

Dessa maneira, a renúncia ao direito da personalidade em si seria vedado, mas a renúncia ao exercício seria possível. Inclusive o próprio Código Civil já prevê tais possibilidades, como no caso do transplante de órgãos ou em relação aos direitos de imagem, de autor, sobre os quais a lei faculta a renúncia ao exercício (STANCIOLI, 2010).

Na mesma linha, ensina que

\begin{abstract}
[...] nem mesmo os ditos "mais valiosos direitos" da pessoa humana (mais valiosos pra quem?) devem ter tratamento diverso. A vida não pode ser um limite para liberdade. Tome-se, por exemplo, quem está em greve de fome. Se irrenunciável o direito à vida, chegará um momento em que se terá abjeta situação de alimentação compulsória do grevista (entubação para fins alimentares). Isso é mais que aviltante: é negar qualquer afirmação plena do sentido da vida em si, para muito além de seus limites biológicos. [...]. Quem pode fazer a articulação de sua vida com os valores que lhe são mais caros (hiperbens) é somente - e tão somente - o titular dos direitos. Pretender que o legislador escolha quais direitos da personalidade podem ter limitações voluntárias é afirmar a possibilidade de hierarquização em abstrato desses direitos, o que contraria toda a lógica hermenêutica contemporânea. (STANCIOLI, 2010, p. 104, grifo no original).
\end{abstract}

Frente a tudo que foi delineado nesse tópico, percebe-se que o diploma civilista brasileiro cristalizou, de maneira expressa, a irrenunciabilidade e a impossibilidade da limitação dos direitos da personalidade. A desconstrução dessa norma perpassa por um esforço argumentativo e hermenêutico que leve a sério o princípio da autonomia da vontade. Ainda, é possível o questionamento: o direito de morrer seria uma renúncia ao exercício aos direitos da personalidade ou a própria afirmação desses direitos? 


\subsection{Código Penal}

A prática da eutanásia é enquadrada no art. 121, parágrafo $1^{\circ}$ do Código Penal brasileiro:

Art. 121. Matar alguém: Pena - reclusão de 6 (seis) a 20 (anos).

$\S 1 .^{\circ}$ Se o agente comete o crime impelido por motivo de relevante valor social ou moral, ou sob o domínio de violenta emoção, logo em seguida a injusta provocação da vítima, o juiz pode reduzir a pena de um sexto a um terço (BRASIL, 1940).

Destarte, aquele que praticar tais condutas cometerá homicídio privilegiado. Entendese que o fato de pôr termo ao sofrimento da vítima, é de relevante valor moral, sendo passível da aplicação do parágrafo $1^{\circ}$ do art. 121 do Código Penal. É o que entende Guilherme Nucci (2013, p. 638): "Sob o ponto de vista legal, qualquer destas formas de matar o paciente, que se encontra angustiado por uma doença, é criminosa. Não se inclui a distanásia, pois esta é forma de prolongar o sofrimento até o fim natural da pessoa humana".

Interessante a ressalva feita pelo referido penalista acerca do debate sobre a possibilidade de acolher a eutanásia como excludente da ilicitude, calcada no consentimento do ofendido. $\mathrm{O}$ consentimento do ofendido é "uma causa supralegal e limitada de exclusão da tipicidade de exclusão da antijuridicidade, permitindo que o titular de um bem ou interesse protegido, considerado disponível, concorde, livremente, com a sua perda" (NUCCI, 2013, p.

257). Assim, depreende-se que é uma causa não prevista expressamente no Código Penal, sendo uma construção doutrinária e jurisprudencial. Destaca-se que há controvérsia sobre sua aceitação, todavia, o entendimento majoritário é a favor de tal construção.

São requisitos essenciais para que se possa reconhecer a ausência de ilicitude pelo consentimento do ofendido: concordância do ofendido; consentimento dado de maneira explícita ou implícita; capacidade para consentir; disponibilidade do bem ou interesse; consentimento dado antes ou durante a prática da conduta do agente; consentimento revogável a qualquer tempo; e o conhecimento do agente acerca do consentimento do ofendido (NUCCI, 2013).

O ponto crucial para se analisar se trata do requisito da disponibilidade do bem ou interesse. Entende-se que a caracterização da indisponibilidade só poderá se aferida caso a caso, levando em consideração os interesses e concepções éticas e morais do particular. Nesse sentido, Guilherme Nucci (2013, p. 258): "Nota-se, pois, que somente o caso concreto poderia determinar a melhor solução para o caso, sem que se fixe, de antemão, ser a vida, sempre, bem indisponível". 
Em relação ao suicídio assistido, o Código Penal dispõe:

Art. 122. Induzir ou instigar alguém a suicidar-se ou prestar-lhe auxílio para que o faça: Pena - reclusão, de 2 (dois) a 6 (seis) anos, se o suicídio se consuma; ou reclusão, de 1 (um) a 3 (três) anos, se da tentativa de suicídio resulta lesão corporal de natureza grave. (BRASIL, 1940).

Assim sendo, observa-se que o Código Penal criminaliza tanto a eutanásia - homicídio privilegiado (art. 121, § 1 $1^{\circ}, \mathrm{CP}$ ) -, quanto o suicídio assistido - auxílio ao suicídio (art. 122, CP) -, ressalvando-se a (im)possibilidade de se utilizar da exclusão da ilicitude pelo consentimento da vítima.

\title{
3.4 Resolução CFM n. 1.805/2006
}

O Conselho Federal de Medicina regulamentou, através da resolução 1.805 de 2006, a prática da ortotanásia no Brasil. Criado em 1951, é um órgão com atribuições constitucionais de fiscalização e normatização da prática médica. (CONSELHO FEDERAL DE MEDICINA, 2014).

O conteúdo da resolução se restringe a dois artigos, quais sejam:

\begin{abstract}
Art. $1^{\circ}$ É permitido ao médico limitar ou suspender procedimentos e tratamentos que prolonguem a vida do doente em fase terminal, de enfermidade grave e incurável, respeitada a vontade da pessoa ou de seu representante legal.

$\S 1^{\circ} \mathrm{O}$ médico tem a obrigação de esclarecer ao doente ou a seu representante legal as modalidades terapêuticas adequadas para cada situação.

$\S 2^{\circ}$ A decisão referida no caput deve ser fundamentada e registrada no prontuário.

$\S 3^{\circ}$ É assegurado ao doente ou a seu representante legal o direito de solicitar uma segunda opinião médica.
\end{abstract}

Art. $2^{\circ} \mathrm{O}$ doente continuará a receber todos os cuidados necessários para aliviar os sintomas que levam ao sofrimento, assegurada a assistência integral, o conforto físico, psíquico, social e espiritual, inclusive assegurando-lhe o direito da alta hospitalar. (CONSELHO FEDERAL DE MEDICINA, 2006).

Acontece que a formalização dessa prática levou ao entendimento, por parte de alguns juristas, de que o Conselho Federal de Medicina não teria competência para tanto, sendo necessário lei para tal fim. Dessa forma, o Ministério Público do Distrito Federal ajuizou uma ação civil pública para obtenção da suspensão dos efeitos da resolução, o que foi deferido, por antecipação de tutela, pelo juiz da $14^{\mathrm{a}}$ Vara da Justiça Federal do Distrito Federal, na medida em que entendeu ser a prática regulada, homicídio por omissão. Algum tempo mais tarde, o Ministério Público Federal, através do seu Procurador Geral, emitiu parecer pela improcedência do pedido e a revogação da tutela antecipada, entendendo que a prática não se tratava de 
eutanásia, mas de ortotanásia, tendo o Conselho Federal de Medicina legitimidade para legislar sobre a matéria. O judiciário acatou o parecer e entendeu que a resolução 1.805/2006 não ofende o ordenamento jurídica brasileiro (SÁ; NAVES, 2011).

Destarte, a prática da ortotanásia passa a ser possível e regulamentada a partir dessa resolução. Apresenta-se, dessa forma, um grande passo frente a implementação de uma maior autonomia privada, bem como representa uma afirmação ao Estado Democrático de Direito.

\subsection{Autonomia para morrer no direito comparado}

Neste tópico estudar-se-á a legislação de alguns países estrangeiros que, em maior ou menor grau, permitem a prática da eutanásia e suicídio assistido. O objetivo é realizar breves apontamentos que permitam a comparação com a legislação brasileira.

\subsubsection{Holanda}

A prática da eutanásia e do suicídio assistido teve sua legislação alterada em $1^{\circ}$ de abril de 2002. Se antes eram condutas típicas, ilícitas e culpáveis, com o advento da Lei da Eutanásia e do Suicídio Assistido - Termination of Life on Request and Assisted Suicide (Review Procedures) Act -, os artigos 293 e 294 do Código Penal holandês passaram a ter seguinte redação:

Art. 293

1. Aquele que acabar com a vida de outra pessoa, motivado por um pedido sério e expresso desta, é passível de pena de prisão não superior a doze anos ou multa de quinta categoria.

2. A infração prevista no primeiro parágrafo não é punível se esta tiver sido cometida por um médico que tenha cumprido as exigências do devido cuidado que se refere o artigo $2^{\circ}$ da Lei da Eutanásia e Suicídio Assistido (Procedimentos de Revisão), bem como informe ao médico legista municipal, de acordo com o artigo $7^{\circ}$, segundo parágrafo da Lei de Enterro e Cremação. (NETHERLANDS, 2014, tradução nossa). ${ }^{2}$

Art. 294

1. Aquele que, intencionalmente, incita outrem a cometer suicídio, é passível de pena de prisão não superior a três anos ou multa de quarta categoria, onde o suicídio se consuma.

2. Aquele que, intencionalmente, auxiliar ou procurar os meios para que outra pessoa cometa suicídio, é passível de pena de prisão não superior a três anos ou multa de quarta categoria, onde o suicídio se consuma. Aplica-se o artigo 293, parágrafo segundo, mutatis mutandis. (NETHERLANDS, 2014, tradução nossa). ${ }^{3}$ 
Destarte, a legislação holandesa despenaliza a prática da eutanásia e do suicídio assistido, desde que cumpridos os requisitos dispostos no art. $2^{\circ}$ da Lei da Eutanásia e Suicídio Assistido. O referido artigo dispõe de sete requisitos que os médicos devem observar, quais sejam: a) ter a convicção que o pedido foi voluntário e refletido; b) ter a convicção que o sofrimento do paciente é duradouro e insuportável; c) ter informado ao paciente sobre a situação em que se encontra e suas perspectivas; d) ter o paciente a convicção que não há outra solução razoável para a situação em que se encontra; e) ter o paciente consultado, pelo menos, um médico independente que o tenha examinado e dado sua opinião escrita sobre os requerimentos de devido cuidado; f) praticar a eutanásia ou o suicídio assistido com o devido cuidado (NETHERLANDS, 2014).

A Lei holandesa ainda permite que o menor entre dezesseis e dezoito anos, que tenha um entendimento razoável sobre os seus interesses, requeiram a prática da eutanásia e do suicídio assistido, desde que seus pais ou responsáveis legais tenham participado do processo ${ }^{4}$ (NETHERLANDS, 2014).

Em relação aos menores de dezesseis e maiores de doze anos que tenham o discernimento necessário, é possível o requerimento da prática da eutanásia e do suicídio assistido, desde que seus pais ou representantes legais concordem com tal medida ${ }^{5}$ (NETHERLANDS, 2014).

Importante destacar que a lei ainda prevê a criação de Comissões Regionais - Regional Review Committes for the Termination of Life on Request and Assisted Suicide - que possuem a função de resguardar e supervisionar todo o procedimento (SÁ; NAVES, 2011).

\footnotetext{
2 Article 293.

1. A person who terminates the life of another person at that other person's express and earnest request is liable to a term of imprisonment of not more than twelve years or a fine of the fifth category.

2. The offence referred to in the first paragraph shall not be punishable if it has been committed by a physician who has met the requirements of due care as referred to in Article 2 of the Termination of Life on Request and Assisted Suicide (Review Procedures) Act and who informs the municipal autopsist of this in accordance with Article 7 second paragraph of the Burial and Cremation Act.

3 Article 294.

1. A person who intentionally incites another to commit suicide is liable to a term of imprisonment of not more than three years or a fine of the fourth category, where the suicide ensues.
} 


\subsubsection{Suiça}

O ordenamento jurídico suíço dispõe sobre a eutanásia e suicídio assistido nos seguintes artigos:

Art. 114. Aquele que, por motivos louváveis, e, em especial, por compaixão para com a vítima, causar a morte desta em seu próprio, genuíno e reiterado pedido, está sujeito a uma pena de prisão não superior a três anos ou a uma multa monetária ${ }^{6}$ (SWITZERLAND, 2014, tradução nossa).

Art. 115. Aquele que, por motivos egoístas, incita ou auxilia alguém a cometer ou tentar cometer suicídio é, caso a outra pessoa depois cometa ou tente cometer suicídio, passível de uma pena de prisão não superior a cinco anos ou a uma multa monetária. ${ }^{7}$ (SWITZERLAND, 2014, tradução nossa).

Dessa maneira, depreende-se que a eutanásia é crime, embora seja punível como pena menos severa se comparada com as outras modalidades do Código Penal Suíço. O suicídio assistido, por sua vez, é permitido, desde que não seja cometido por motivos egoísticos e desde que cumpra os devidos cuidados.

Importante destacar a presença de duas grandes associações de assistência ao suicídio na Suiça: EXIT e Dignitas, ambas com grande número de associados. A grande diferença entre elas é que na primeira não há qualquer custo e apenas aceitam cidadão suíços, ao passo que a segunda aceita cidadão estrangeiros e possui custos econômicos. Tratam-se de associações de caráter humanitário que, através de uma rigorosa seleção e requisitos rígidos, auxiliam a pessoa a realizar o suicídio (SWISSINFO, 2014).

\footnotetext{
2. A person who intentionally assist in the suicide of another or procures for that other person the means to commit suicide, is liable to a term of imprisonment of not more than three years or a fine of the fourth category, where the suicide ensues. Article 293 second paragraph applies mutatis mutandis.

4 . If the minor patient has attained an age between sixteen and eighteen years and may be deemed to have a reasonable understanding of his interests, the physician may carry out the patient's request for termination of life or assisted suicide, after the parent or the parents exercising parental authority and/or his guardian have been involved in the decision process.

5 4. If the minor patient is aged between twelve and sixteen years and may be deemed to have a reasonable understanding of his interests, the physician may carry out the patient's request, provided always that the parent or the parents exercising parental authority and/or his guardian agree with the termination of life or the assisted suicide. The second paragraph applies mutatis mutandis.

6 Art. 114. Any person who for commendable motives, and in particular out of compassion for the victim, causes the death of a person at that person's own genuine and insistent request is liable to a custodial sentence not exceeding three years or to a monetary penalty.

7 Art. 115. Any person who for selfish motives incites or assists another to commit or attempt to commit suicide is, if that other person thereafter commits or attempts to commit suicide, liable to a custodial sentence not exceeding five years or to a monetary penalty.
} 


\subsubsection{Bélgica}

A Bélgica legalizou a eutanásia através de uma lei publicada em 22 de junho 2002. A referida lei não faz menção à prática do suicídio assistido, na medida em que delimita, em seu art. $2^{\circ}$, que se trata do fim da vida praticado por terceiro, a pedido da vítima (BELGIE, 2014).

Trata-se de uma legislação muito semelhante à holandesa, trazendo requisitos que devem ser observados pelo médico, entre os quais: a) informar o paciente sobre sua saúde e sua vida, bem como sobre todas as opções terapêuticas restantes, cuidados paliativos e discutir suas implicações; b) ser a decisão do paciente razoável e voluntária; c) haver certeza da continuidade do sofrimento físico ou psicológico do paciente; d) consultar outro médico sobre a natureza grave e incurável da doença; f) garantir que o paciente tenha tido tempo para falar com as pessoas que ele queira (BELGIE, 2014).

A maior polêmica dessa lei se deu recentemente, através de uma alteração em 2014 que prevê a possibilidade da prática da eutanásia independentemente de idade. Destarte, a lei belga dispensou um limite mínimo para tal prática. A previsão antes dessa modificação, se restringia à adultos e menores emancipados.

Assim dispõe a lei belga sobre eutanásia:

$7^{\circ}$. Se o paciente for menor de idade não emancipado, a criança ou adolescente deverá
consultar um psiquiatra ou psicólogo e informá-lo das razões da consulta. O
especialista observará o prontuário médico, examinará o paciente, verificará a
habilidade de julgamento do menor e o certificará por escrito. O médico deve informar
ao paciente e seus representantes legais do resultado desta consulta. Durante entrevista
com os representantes legais do menor, o médico passará todas as informações
referidas nos parágrafos $2^{\circ}$ e $1^{\circ}$, bem como se certificará de que eles deram o seu
consentimento sobre o pedido do paciente menor ${ }^{8}$ (BELGIE, 2014, tradução nossa).

Em todos os casos o pedido deve ser voluntário, refletido e repetido, não sendo resultado de pressão externa. Deve ainda se tratar de condição médica sem esperança, em que haja constante e insuportável sofrimento físico ou psicológico que não possa ser aliviado, e que seja causado por acidente ou doença (BELGIE, 2014).

\footnotetext{
$87^{\circ}$ indien de patiënt een niet-ontvoogde minderjarige is, bovendien een kinder- en jeugdpsychiater of een psycholoog raadplegen en hem op de hoogte brengen van de redenen voor deze raadpleging.De geraadpleegde specialist neemt kennis van het medisch dossier, onderzoekt de patiënt, vergewist zich van de oordeelsbekwaamheid van de minderjarige en attesteert dit schriftelijk.De behandelende arts brengt de patiënt en zijn wettelijke vertegenwoordigers op de hoogte van het resultaat van deze raadpleging. Tijdens een onderhoud met de wettelijke vertegenwoordigers van de minderjarige bezorgt de behandelende arts hen alle in $\S 2,1^{\circ}$, bedoelde informatie, en vergewist hij zich ervan dat zij hun akkoord geven betreffende het verzoek van de minderjarige patiënt.
} 
A lei belga ainda traz previsões das diretivas antecipadas de vontade, a fim de que sejam utilizadas na impossibilidade de manifestação do paciente, bem como prevê a criação de um Comitê de Controle e Avaliação Federal para acompanhamento e supervisão dos casos de eutanásia (BELGIE, 2014).

\subsubsection{Uruguai}

A legislação uruguaia prevê a possibilidade do perdão judicial nos casos de homicídio piedoso, embora não haja tal previsão nos casos de suicídio assistido:

37. Os juízes têm o poder de isentar de punição o sujeito de bons antecedentes, autor de um homicídio realizado por motivos de piedade, através de repetidas súplicas da vítima ${ }^{9}$ (URUGUAY, 2014, tradução nossa).

315. Aquele que auxiliar ou incitar outrem à cometer suicídio, caso ocorra a morte, será punido com pena de prisão de seis meses a seis anos de prisão. A pena máxima poderá ser ultrapassada até o limite de doze anos, quando a infração for cometida em relação a uma criança menor de dezoito anos, ou em relação a um sujeito incapaz por doença mental, abuso de álcool ou uso de $\operatorname{drogas}^{10}$ (URUGUAY, 2014, tradução nossa).

Interessante destacar o caso desse país sul-americano que, embora não permita tais práticas, dá uma maior margem de atuação para o juiz. Dessa forma, a possibilidade de perdão judicial nos casos de eutanásia, já representa uma maior efetivação da autonomia privada. Tratase de um meio termo entre a descriminalização e a proibição.

\section{APONTAMENTOS ZETÉTICOS}

O que é mais racional, parar a máquina, quando a obra que dela se exigia foi completada - ou deixá-la funcionando até que pare por si mesma, isto é, até que se estrague? $O$ segundo caso não é um esbanjamento dos custos de manutenção, um abuso de energia e atenção daqueles que dela cuidam? Não é aí jogado fora o que muito se necessita em outra parte? Não se cria até mesmo uma espécie de desdém pelas máquinas, quando muitas delas são mantidas e entretidas inutilmente? (NIETZSCHE, 2008, p. 247).

\footnotetext{
9 Del homicio piadoso. Los Jueces tieene la facultad de exonerar de castigo al sujeto de antecedentes honorables, autor de um homicio, efectuado por móviles de piedad, mediante súplica reiteras de la victima.

10 El que determinare a otro al suicidio o le ayudare a cometerlo, si ocurriere la muerte, será castigado con seis meses de prisión a seis años de penitenciaría. Este máximo puede ser sobrepujado hasta el límite de doce años, cuando el delito se cometiere respecto de un menor de dieciocho años, o de un sujeto de inteligencia o de voluntad deprimidas por enfermedad mental o por el abuso del alcohol o el uso de estupefacientes.
} 
Certamente, ao estudar a eutanásia e o suicídio assistido sob a perspectiva zetética, uma grande questão se ressalta: a moralidade.

A análise filosófica pode ter diferentes orientações. Dessa sorte, há aqueles que “[...] admitem, por razões variadas, a validade geral dos termos em que a discussão está posta, empenhando-se em construir suas soluções para ela de acordo com os limites inerentes a esses termos" (PIMENTA NETO, 2006, p. 16). Assim, o questionamento seria sobre a moralidade ou imoralidade da prática da eutanásia e do suicídio assistido. Por outro lado, “[...] há os que duvidam da legitimidade das instâncias em que ela foi formulada, preferindo antes investigar o mérito das próprias perguntas a propor respostas para elas" (PIMENTA NETO, 2006, p. 16). Aqui, o questionamento seria sobre o que se entende por moralidade e imoralidade.

Dentre os segundos, destaca-se o pensamento de Friedrich Nietzsche, que será objeto de estudo nessa seção. Dessa maneira, o objetivo é a construção de uma interpretação (dentre as várias possíveis), que fundamente a possibilidade da eutanásia e do suicídio assistido. Para tanto, adotar-se-á como referencial teórico - porém não se restringindo a este -, o estudo feito por Richard Schacht (1983), em que se destrincha a visão nietzschiana a respeito da moralidade.

Parte-se da premissa segundo a qual o óbice à legitimação da morte própria, em termos filosóficos/zetéticos, seria sua imoralidade, uma vez ser a vida um valor absoluto, não podendo ser relativizada ou renunciada.

A priori, faz-se necessário a identificação do conceito do moral e moralidade no pensamento de Nietzsche. Dessarte, moralidades são fenômenos sociais, entendidos como

[...] espécies de avaliações, as quais comumente encontram articulação e expressão nos preceitos prescrevendo e proibindo vários tipos de conduta, defendendo ou condenando certos padrões ou traços dos seres humanos, os quais são refletidos em atitudes que seus aderentes têm e avaliam que estão dispostos a fazer com relação a tais assuntos ${ }^{11}$ (SCHACHT, 1983, p. 426, tradução nossa).

11 [...] species os valuations, which commonly find articulation and expression in precepts prescribing and proscribing various courses of conduct and advocating or condemning certain possible types or traits of human beings, and which are reflected in attitudes their adherents have and assessments they are disposed to make with respect to such matters. 
A chave para a compreensão da moralidade no pensamento do referido filósofo, parte da constatação de que não há uma moral absoluta, um único fenômeno moral, ou ainda, um fato moral, mas apenas uma interpretação de tal fenômeno que é, por si só, de origem extra moral. Assim, não há uma verdade moral metafísica, mas uma pluralidade de moralidades. Não obstante, observa-se, durante a história da humanidade, que apenas um tipo de moralidade prevaleceu e se tornou dominante, encontrando expressão em sentimentos, valores, atitudes, crenças, leis, direitos e obrigações. Isso é o que Nietzsche chama de preconceito moral (SCHACHT, 1983).

Dessa maneira, a ideia de imoralidade frente a eutanásia e o suicídio assistido é apenas uma das moralidades que é possível se defender. Certo é que se trata da moral dominante, fruto da história da sociedade e, principalmente, do cristianismo. Não se trata de uma moralidade incorreta ou desprezível, apenas não é a única. Trata-se de uma moral que deve ser exercida entre os seus aderentes, mas não à totalidade de seres humanos. Em suas palavras:

A moral é hoje na Europa uma moral de animal de rebanho: - e portanto, na nossa opinião, apenas uma espécie particular de moral humana, ao lado ou antes ou depois da qual são possíveis ou deveriam ser possíveis muitas outras morais, sobretudo morais superiores (NIETZSCHE, 1998b, p. 109, grifo no original).

O problema é que a moral dominante tem a pretensão de ser absoluta, afirmando não haver moral fora dela. Dessarte, tudo o que se encontrar fora do seu âmbito de incidência é considerado mau, hostil ou cruel. Nesta visão, só é bom ou moral, aquele que agir de acordo com o padrão de pensamento e conduta determinado externamente. Assim, o indivíduo moral é aquele que espera o fim de sua vida de forma natural, não importando seu sofrimento ou desejo, ao passo que imoral é aquele que escolhe, racionalmente e de acordo com sua concepção de vida boa, o momento de sua partida.

É contra esse tipo de moralidade que Nietzsche se insurge. Ao invés de uma "moralidade de rebanho", propõe-se uma moralidade superior, para o além-do-homem. Essa moralidade somente pode ser atingida por cada ser humano, em sua individualidade, como criadores, sendo a única maneira de se atingir a auto realização (SCHACHT, 1983).

A moralidade, quando entendida como

[...] 'modo de vida' e de 'encantamento da vida', ajustada para tomar conta das diferentes 'condições de preservação e desenvolvimento' de diferentes tipos de seres humanos, deixa de ser uma 'mentira' prejudicial e uma 'ilusão' perigosa, adquirindo legitimidade e significado à luz de sua filosofia antropológica e teoria dos valores ${ }^{12}$ (SCHACHT, 1983, p. 419, tradução nossa). 
É essa a ideia de moralidade que Nietzsche defende, em suma, aquela em que há o fortalecimento e o encantamento da vida, que eleva o homem às alturas, que afirma sua existência, que admite o poder de livre desenvolvimento do homem e que o possibilita se tornar aquele que pretende ser. Essa escolha cabe a cada homem, como criador, através de sua vontade de poder.

Poder-se-ia alegar que essa pluralidade de moralidades levaria a humanidade à um caos, uma vez que cada indivíduo teria sua própria tábua de valores. Tal ideia, contudo, é equivocada, uma vez não se tratar de egoísmo, relativismo ou determinismo. A resposta é dada por Nietzsche (1998a, p. 89) através de um questionamento feito por Zaratustra: "Podes dar a ti mesmo o teu mal e o teu bem e suspender a tua vontade por cima de ti como uma lei? Podes ser o teu próprio juiz e vingador da tua lei?"

À respeito do assunto, manifesta-se Olímpio Pimenta Neto (2006, p. 25-26):

O que a sabedoria afirmativa aspira a mostrar é justamente que um mundo assim concebido resulta num espetáculo que demanda atores à sua altura. Não é por não dispormos de um fundamento de última instância para nossas decisões que estamos fadados à anarquia ou à desolação. A responsabilidade que emerge então é a que se exige de um criador, capaz de sustentar a partir de si mesmo os compromissos que firmou.

Frente a tudo que foi exposto, é possível resumir o pensamento nietzschiano acerca da moralidade na seguinte passagem:

[...] ao invés de procurar estabelecer alguma 'lei universal' ou 'imperativo categórico', nos 'limitemos' a algo completamente diferente, ao mesmo tempo menos 'egoísta' e mais importante: 'a criação das nossas próprias novas tábuas de valores sobre o que é bom', como 'seres humanos que são novos, únicos, incomparáveis, que se dão as próprias leis, que criam a si próprios' e, então, 'tornam-se aqueles que são'. ${ }^{13}$ (SCHACHT, 1983, p. 466, tradução nossa).

Outra construção que corrobora esse posicionamento é a ideia de tragédia, desenvolvida por Nietzsche em seus primeiros escritos. Tal ideia é posta em choque com a cultura platônicocristã, predominante na cultura ocidental. Nietzsche contrapõe-se ao pensamento de que existe um mundo real, a ser atingindo através do intelecto e que o mundo em que vivemos de fato, o mundo aparente, seria de menor importância e valor. Da mesma forma, combate o pensamento de que a vida mundana deve ser renegada, afastada para que se possa transcender.

Tais concepções afastam o homem da própria vida, o enfraquecendo. É em virtude dessa visão que o filósofo retorna a ideia de tragédia desenvolvida pelos gregos do período trágico. 
Esse povo concebeu o mundo da forma como ele é, o celebrando em toda sua completude, seja na felicidade e, principalmente, nas dores.

Oswaldo Giacoia Junior (2000, p. 59) expressa bem o espírito trágico da filosofia nietzschiana:

Somente quando sua existência terrena puder deixar de ser vivida sob a ótica do juízo e da condenação, como padecimento e expiação, como ascese, pela qual se conquista a felicidade eterna; somente então poderá o homem instituir-se para si um ideal que seja também o sentido da terra, liberto da fantasia transcendente de um além-domundo, com a qual ele entorpece a dor de sua finitude, tragédia de sua existência.

Ora, a vida é uma tragédia! Só há vida em contraposição à morte, sendo uma dualidade inseparável. Somente aceitando essa dualidade é que se pode chegar a uma existência afirmativa da vida:

[...] se o que o mundo oferece aos melhores de nós, e também ao melhor em nós, é o desenrolar dos conflitos, nos quais tudo o que podemos de excelente reluz quando lançado, a réplica mais verdadeira a este mundo é a criação de outros tantos enredos, em chave épica, trágica ou cômica. Neles é forjada nossa gratidão pela existência. [...]. Ao invés de cogitar sobre corrupção e queda, preparar-se para dar conta da pluralidade do mundo, ultrapassando a estreiteza de rubricas binárias como certo e errado, bem e mal. Não é à toa que a figura afirmativa típica é a do narrador, artista ou não, que se serve de tudo o que há para compor seus festivais (PIMENTA NETO, 2006, p. 21).

Ademais, Nietzsche se manifestou especificamente à respeito da morte voluntária ou morte racional (NIETZSCHE, 1998a, p. 98-100; NIETZSCHE, 2008, p. 247-248). Em contraponto à morte natural, o filósofo entende que essa é "[...] o suicídio da natureza, isto é, a destruição do ser mais racional, pelo elemento mais irracional que a ele está ligado", completando que "[a] sábia organização e disposição da morte faz parte da moral do futuro, agora incompreensível e imoral na aparência, mas cuja a aurora é uma indescritível felicidade observar" (NIETZSCHE, 2008, p. 247-248).

\footnotetext{
12 [...] 'means of life' and of 'the enhancement of life', and adjusted so as to take account of the differing 'conditions of preservation and development' os different types of human beings, it ceases to be a harmful 'lie' and dangerous 'illusion', and acquires legitimacy and significance in the light of his philosophical anthropology and value theory.

13 [...] in place of seeking to establish some 'universal law' or 'categorical imperative', we 'limit ourselves' to something quite different, at once less 'selfish' and more important: 'to the creation of our own new tables of what is good' as 'human beings who are new, unique, incomparable, who give themselves laws, who create themselves' and so 'become those we are'.
} 
A partir dessas considerações, pretendeu-se evidenciar a possibilidade da autonomia para morrer no pensamento de Friedrich Nietzsche. A partir da concepção de que não há uma moral absoluta, sendo cabível a cada ser humano buscar sua auto realização, entende-se plenamente cabível uma moral que privilegie o racionalismo, a autonomia e a boa morte. Ainda, se parte-se da ideia de vida como tragédia, apenas na aceitação dessa é que se torna possível a celebração e afirmação da vida. Destarte, conclui-se que é possível o exercício da morte voluntária, podendo ser essa mais uma forma de afirmação da existência.

Finaliza Nietzsche (1998a, p. 100): "Na vossa morte ainda deverão fulgir o vosso espírito e a vossa virtude, tal como um rubro pôr-do-sol sobre a terra; do contrário, a vossa morte se vos terá malogrado".

\section{CONCLUSÃO}

Frente a tudo que foi delineado ao longo desse artigo, conclui-se pela possibilidade da fundamentação da prática da eutanásia e do suicídio assistido, tanto em termos dogmáticos, quanto em termos zetéticos.

No aspecto dogmático, a fundamentação da prática da eutanásia e do suicídio assistido perpassa pela superação de um paradigma. O caminhar em direção a um pós-positivismo jurídico e um Estado Democrático de Direito aponta mudanças estruturais e hermenêuticas na Ciência do Direito.

É certo que a legislação positivada indica uma vedação às referidas práticas: a Constituição da República prega a indisponibilidade da vida, o Código Civil dispõe a indisponibilidade e irrenunciabilidade dos direitos da personalidade, o Código Penal criminaliza tais condutas. Não obstante, é necessário a indagação: o Direito se restringe à norma positivada?

Certamente o tex to normativo é de fundamental importância para o estudo dogmático do Direito - é o inegável ponto de partida. Contudo, a hermenêutica leva o interprete para além do ponto de partida, buscando o sentido mais adequado para o caso concreto. Vivencia-se a superação do positivismo clássico. Destarte, o direito não se encontra plenamente dado, completo e fechado. A ascensão dos princípios jurídicos ao status de normas cogentes, indica a necessidade de adequação das regras.

É necessário pensar a partir do caso - e não em um esquema prévio, a priori. Desse modo, a fundamentação parte da afirmação dos princípios da dignidade da pessoa humana, da 
autonomia privada, do pluralismo. Apenas é possível a defesa do direito de morrer através de uma construção dogmática sólida, que não menospreze os fundamentos constitucionais da República Federativa do Brasil.

Na perspectiva zetética, tendo como fundamento o pensamento de Friedrich Nietzsche, apontou-se que a afirmação da morte pode ser também uma afirmação da vida. O filósofo alemão evidencia a existência de uma pluralidade de moralidades, não existindo uma que seja a correta. Cabe a cada ser humano, na sua própria grandeza, estabelecer sua tábua valorativa sem que isso gere um relativismo insustentável. Dessa maneira, a prática da eutanásia e do suicídio assistido poderia estar contida em uma das moralidades existentes. Ademais, se a vida é uma tragédia, cabe a cada pessoa vivenciá-la, celebrar as tragédias como outrora fizeram os gregos. Destarte, a autonomia para morrer pode ser plenamente uma das possibilidades de uma vida afirmativa.

Assim, esse artigo buscou apresentar uma fundamentação jurídica e filosófica para a prática da eutanásia e suicídio assistido. Ao final, entende-se cumprido o objetivo, na medida em que possibilitou uma perspectiva engrandecedora do ser humano, enaltecedora de sua autonomia, e que entende a pessoa como ser racional, dialógico e livre.

\section{REFERÊNCIAS}

BELGIE. Wet betreffende de euthanasie. Disponível em: <http://www.ejustice.just.fgov.be/cgi_loi/change_lg.pl?language=nl\&la=N\&cn=2002052837 \&table_name=wet $>$ Acesso em: 19 jun. 2014.

BLACKBURN, Simon. Dicionário Oxford de filosofia. Trad. Desidério Murcho. Rio de Janeiro: Jorge Zahar Editora, 1997. p. 437.

BRASIL. Código Penal (1940). Constituição da República Federativa do Brasil. In: CURIA, Luiz Roberto; CÉSPEDES, Livia; NICOLETTI, Juliana. Vade Mecum Saraiva. 15. ed. São Paulo: Saraiva, 2013. p. 2028.

BRASIL. Constituição (1988). Constituição da República Federativa do Brasil. In: CURIA, Luiz Roberto; CÉSPEDES, Livia; NICOLETTI, Juliana. Vade Mecum Saraiva. 15. ed. São Paulo: Saraiva, 2013. p. 2028.

BRASIL. Código Civil (2002). Código Civil. 16. ed. São Paulo: RT, 2014. p. 2042. 
BRASIL. Supremo Tribunal Federal. Ação Direta de Inconstitucionalidade 2.649-6 DF (2008). Relatora: Min. Carmén Lúcia. Disponível em: $<$ http://redir.stf.jus.br/paginadorpub/paginador.jsp?docTP=AC\&docID=555517>. Acesso em: 13 jun. 2014. p. 45.

BRASIL. Supremo Tribunal Federal. Arguição de Descumprimento de Preceito Fundamental 54 DF (2012). Relator: Min. Marco Aurélio. Disponível em: <http://redir.stf.jus.br/paginadorpub/paginador.jsp?docTP=TP\&docID=3707334> Acesso em: 15 jun. 2014. p. 433.

CONSELHO FEDERAL DE MEDICINA. A instituiçãa. Disponível em: <http://portal.cfm.org.br/index.php?option=com_content\&view=article\&id=20671\&Itemid=2 3> Acesso em: 16 jun. 2014.

CONSELHO FEDERAL DE MEDICINA. Resolução CFM n 1.805 (2006). Disponível em: < http://www.portalmedico.org.br/resolucoes/cfm/2006/1805_2006.htm> Acesso em: 16 jun. 2014.

DALLARI, Dalmo de Abreu. Elementos de teoria geral do Estado. 29. ed. São Paulo: Saraiva, 2010. p. 314.

FERNANDES, Bernardo Gonçalves. Curso de Direito Constitucional. Rio de Janeiro: Lumen Juris, 2010. p. 1071.

FERRAZ JUNIOR, Tercio Sampaio. Introdução ao estudo do direito: técnica, decisão, dominação. 5. ed. São Paulo: Atlas, 2007. p. 385.

GIACOIA JUNIOR, Oswaldo. Nietzsche. São Paulo: Publifolha, 2000. p. 92.

MORAES, Alexandre de. Constituição do Brasil interpretada e legislação constitucional. São Paulo: Atlas, 2002. p. 2924.

NETHERLANDS. Termination of Life on Request and Assisted Suicide (Review Procedures) Act. Disponível em:

<http://www.schreeuwomleven.nl/abortus/text_of_dutch_euthanasia_law.doc> Acesso em: 19 jun. 2014.

NIETZSCHE, Friedrich Wilhelm. Assim falou Zaratustra: um livro para todos e para ninguém. 9 edição. Tradução Mário de Silva. Rio de Janeiro: Civilização Brasileira, 1998a. p. 381.

NIETZSCHE, Friedrich Wilhelm. Para além de bem e mal. 7. ed. Lisboa: Guimarães Editores, 1998b. p. 234.

NIETZSCHE, Friedrich Wilhelm. Humano, demasiado humano: um livro para espíritos livres volume 2. Tradução, notas e posfácio Paulo César de Souza. São Paulo: Companhia das Letras, 2008. p. 363. 
NUCCI, Guilherme de Souza. Código penal comentado. 13. ed. São Paulo: Editora Revista dos Tribunais, 2013. p. 1390.

PESSINI, Leocir; BARCHIFONTAINE, Christian de Paul de. Problemas atuais de bioética. 8 . ed. São Paulo: Loyola, 2007. p. 584.

PIMENTA NETO, Olímpio José. Livro de Filosofia: ensaios. Belo Horizonte: Tessitura Editora, 2006. p. 85.

RUGER, André; RODRIGUES, Renata de Lima. Autonomia como princípio jurídico estrutural. In: FIUZA, César; NAVES, Bruno Torquato de Oliveira; SÁ, Maria de Fátima Freire de; (coord.). Direito Civil: Atualidades II. Belo Horizonte: Del Rey, 2007. p. 55-71.

SÁ, Maria de Fátima Freire de; NAVES, Bruno Torquato de Oliveira. Manual de Biodireito. Belo Horizonte: Del Rey, 2011. p. 376.

SÁ, Maria de Fátima Freire de; MOUREIRA, Diogo Luna. Autonomia para morrer: eutanásia, suicídio assistido e diretivas antecipadas de vontade. Belo Horizonte: Del Rey,

2012. p. 248.

SCHACHT, Richard. Nietzsche. Col. The arguments of the philosophers. London: Routledge, 1983.

SIQUEIRA-BATISTA, Rodrigo; SCHARAMM, Fermin Roland. Eutanásia: pelas veredas da morte e da autonomia. Revista Ciência \& Saúde Coletiva, 2004. p. 31-41.

SOUZA, Iara Antunes de. Aconselhamento genético e responsabilidade civil: as ações por concepção indevida (wrongful conception), nascimento indevido (wrongful birth) e vida indevida (wrongful life). Belo Horizonte: Arraes Editores, 2014. p.150.

STANCIOLI, Brunello Souza. Relação jurídica médico-paciente. Belo Horizonte: Del Rey, 2004. p. 123.

STANCIOLI, Brunello Souza. Renúncia ao exercício de direitos da personalidade ou como alguém se torna o que quiser. Belo Horizonte: Del Rey, 2010. p. 208.

SUOTÔNIO. Roma galante: chronica escandalosa da côrte dos doze Cezares. Trad. De Guilherme Rodrigues. Disponível em:

<https://archive.org/details/romagalantechron00suetuoft>. Acesso em: 5 jul. 2014.

SWISSINFO. Mitos e realidades sobre o suicídio assistido na Suíça. Disponível em: <http://www.swissinfo.ch/por/arquivo/Mitos_e_realidades_sobre_o_suicidio_assistido_na_Su ica.html?cid=893224> Acesso em: 19 jun. 2014.

SWITZERLAND. Swiss Criminal Code. Disponível em: <http://www.legislationline.org/documents/section/criminal-codes> Acesso em 19 jun. 2014.

URUGUAY. Código Penal. Disponível em: <http://www.parlamento.gub.uy/Codigos/CodigoPenal/Cod_Pen.htm> Acesso em: 19 jun. 2014. 